\title{
MÉTODOS DE AMOSTRAGEM E ANÁLISE PARA COMPOSTOS REDUZIDOS DE ENXOFRE ATMOSFÉRICO
}

\author{
Lícia P. S. Cruz e Vânia P. Campos* \\ Departamento de Química Analítica, Instituto de Química, Universidade Federal da Bahia, Campus Universitário de Ondina,
} 40170-290 Salvador - BA, Brasil

Recebido em 16/3/07; aceito em 18/9/07; publicado na web em 19/3/08

\begin{abstract}
SAMPLING AND ANALYTICAL METHODS FOR ATMOSPHERIC REDUCED SULPHUR COMPOUNDS. This work presents a review of sampling and analytical methods that can be applied to atmospheric traces of reduced sulphur compounds (RSC) in the atmosphere. Sampling methodology involving discontinuous methods with preconcentration is mostly used. For the most part, adsorption on solids and cryogenic capture are applied as a procedure. The analysis of these compounds has been done mainly by gas chromatography with FPD, fluorescence and spectrophotometry. Advantages and disadvantages of the methodologies are also mentioned in this paper, aiming to guide the reader towards the most appropriate choice of a sampling and analytical method for RSCs.
\end{abstract}

Keywords: reduced sulphur compounds; air sampling; trace analysis.

\section{INTRODUÇÃO}

A amostragem de componentes traços atmosféricos tem se tornado um desafio constante, pois sendo o ar um sistema heterogêneo e multifásico, constituído de gases, partículas líquidas, sólidas e heterogêneas, cuja composição varia espacial e temporalmente, é provavelmente a matriz ambiental mais difícil para se obter amostras representativas. ${ }^{1}$

A exigência por técnicas exatas, confiáveis e sensíveis para o monitoramento de componentes traços atmosféricos tem aumentado continuamente. As razões para isto incluem não apenas a crescente preocupação com a qualidade ambiental, mas também o fato da poluição atmosférica não ser um problema apenas local. Adicionalmente, informações seguras sobre componentes do ar são necessárias para o entendimento do seu comportamento químico e físico na atmosfera, e para identificar, solucionar ou controlar um problema ambiental.

Exceto os componentes principais que se mantêm constantes na atmosfera através de suas taxas de formação e de decaimento, as espécies químicas encontram-se geralmente em concentrações muito baixas na atmosfera, devido a processos de dispersão e diluição. Desta forma, o método de amostragem utilizado deve ser o mais eficiente possível, devendo-se tomar cuidados específicos para evitar problemas, que uma vez ocorridos nesta etapa, não poderão ser corrigidos posteriormente durante a análise.

De maneira geral, entre os aspectos mais relevantes a serem considerados no planejamento de uma amostragem estão: os objetivos do trabalho, que influenciam diretamente na escolha do método de amostragem, ao lado das concentrações esperadas do analito, a disponibilidade de dados meteorológicos, o transporte e estocagem das amostras e as condições de análise.

Um sistema ideal de amostragem de ar deve atender aos seguintes requisitos: a amostra deve ser representativa da matriz; o procedimento de amostragem deve ser simples, para que possa ser utilizado em qualquer região (inclusive em áreas remotas); o tamanho da amostra obtida deve ser compatível com a sensibilidade do método analítico e, não devem ocorrer perdas e/ou degradação da

*e-mail: vaniaroc@ufba.br amostra durante o período de amostragem, ou durante o tempo entre a amostragem e a análise. ${ }^{1,2} \mathrm{~A}$ escolha inadequada do método pode levar à formação de artefatos durante a amostragem e no período anterior à análise química, gerando falsos resultados.

Os compostos de enxofre existem nas formas oxidada e reduzi$\mathrm{da}$, com estados de oxidação variando de $-2 \mathrm{a}+6$. Os principais compostos voláteis sob forma reduzida são: sulfeto de hidrogênio $\left(\mathrm{H}_{2} \mathrm{~S}\right)$, sulfeto de carbonila (COS), dissulfeto de carbono $\left(\mathrm{CS}_{2}\right)$, sulfeto de metila $\left(\mathrm{CH}_{3} \mathrm{SH}\right)$, sulfeto de dimetila $\left(\mathrm{CH}_{3} \mathrm{SCH}_{3}, \mathrm{DMS}\right)$, e dissulfeto de dimetila ( $\left.\mathrm{CH}_{3} \mathrm{SSCH}_{3}, \mathrm{DMDS}\right)$, também chamados de compostos reduzidos de enxofre (CRE). A amostragem e a análise destes compostos são difíceis, pois os mesmos são voláteis à temperatura ambiente e alguns são solúveis em água. Além disso, estão presentes na atmosfera (remota e/ou poluída) em concentrações muito baixas, na faixa de $\mathrm{ng} \mathrm{m}^{-3}$ a $\mu \mathrm{g} \mathrm{m}^{-3}$, sendo geralmente necessária uma etapa de pré-concentração na amostragem, para melhorar a sensibilidade do método, e/ou o isolamento do composto de interesse, para reduzir ou eliminar possíveis interferências. São compostos bastante reativos e facilmente adsorvidos sobre superfícies. Assim, todos os materiais que os CRE entram em contato durante a amostragem e análise devem ser inertes, para manter a integridade da amostra, evitando perdas do analito por adsorção, oxidação ou difusão para as paredes dos recipientes. ${ }^{3}$

Nas últimas três décadas a demanda referente à determinação de compostos de enxofre no ambiente tem sido crescente, devido a fatores, como por exemplo: 1) a preocupação com a qualidade ambiental. Compostos de enxofre voláteis constituem uma fonte significativa de poluição atmosférica biogênica e antrópica e, conseqüentemente, podem ser responsáveis por danos ambientais, incluindo participação na deposição ácida. ${ }^{4}$ Além disso, estes compostos podem afetar a química da estratosfera, pois o COS que é produzido na troposfera pode ser transportado para aquela camada superior, onde é convertido a $\mathrm{SO}_{2}$ e depois a ácido sulfúrico e outras finas partículas de sulfato. 2) o papel desses compostos em ciclos químicos globais. Sulfeto de dimetila (DMS), um importante composto de enxofre produzido nos oceanos, tem participação crítica no ciclo global de enxofre e no balanço da radiação da Terra. ${ }^{5}$ 3) os problemas de odor. Alguns deles, embora presentes na atmosfera em níveis de traços são responsáveis por odor muito desagradável. 
É o caso do $\mathrm{H}_{2} \mathrm{~S}$, que confere mau cheiro às áreas próximas à sua fonte de emissão, sendo perceptível ao nariz humano em concentrações muito baixas (a partir de $0,7 \mu \mathrm{g} \mathrm{m}^{-3}$ ). ${ }^{6}$ Mesmo só exercendo efeitos tóxicos em concentrações acima de $14 \mathrm{mg} \mathrm{m}^{-3}$, a presença de $\mathrm{H}_{2} \mathrm{~S}$ na atmosfera fere as leis ambientais que proíbem quaisquer emissões de odores.

Este artigo se propõe a apresentar uma revisão crítica dos métodos de amostragem e análise que têm sido usados para compostos reduzidos de enxofre na atmosfera, buscando orientar o leitor para uma escolha adequada, ao tempo em que também são discutidos os aspectos mais gerais da amostragem de compostos gasosos.

\section{FONTES NATURAIS E ANTRÓPICAS E PROCESSOS DE DECAIMENTO DE COMPOSTOS REDUZIDOS DE ENXOFRE NA ATMOSFERA}

Compostos reduzidos de enxofre (CRE) são emitidos para a atmosfera tanto por fontes naturais como antrópicas. Andreae e Jaeschke $^{7}$ estimaram o fluxo total de compostos de enxofre (sem incluir sulfato marinho) para a atmosfera como $158 \pm 30 \mathrm{Tg} \mathrm{S}$ ano $^{-1}$, sendo $8 \%$ deste fluxo oriundos de atividades geotérmicas como vulcões, $32 \%$ da biosfera (oceanos, solos, plantas e manguezais) e $60 \%$ de fontes antrópicas (incluindo queima de biomassa). Segundo Cullis e Hirschler ${ }^{8}$ a estimativa do fluxo de compostos de enxofre para a atmosfera decorrente de atividades humanas é em torno de $93 \pm 15 \mathrm{Tg} \mathrm{S}$ ano ${ }^{-1}$, sendo a parcela referente aos CRE muito pequena $\left(3,0 \pm 2 \mathrm{Tg} \mathrm{S} \mathrm{ano}^{-1}\right)$, não representando mais que $3 \%$ do total emitido pelas diversas fontes antrópicas. O $\mathrm{SO}_{2}$ é o principal composto de enxofre emitido por essas fontes (94\%). Por outro lado, as emissões naturais de compostos de enxofre $\left(65 \pm 25 \mathrm{Tg} \mathrm{S}\right.$ ano $^{-1}$, não incluindo sulfato marinho) são predominantemente na forma de compostos reduzidos. ${ }^{4}$

Estimativas de fluxo de CRE de diferentes fontes naturais foram resumidas por Andreae e Jaeschke. ${ }^{7}$ Aneja, ${ }^{9}$ que também estimou o fluxo desses compostos proveniente daquelas fontes, admitiu que são inúmeras as incertezas envolvidas nestas estimativas, pois é necessário considerar os mais diferentes ambientes onde a atividade biológica propicia a emissão de compostos voláteis de enxofre, além da existência de problemas técnicos, quando não se dispõe de métodos de amostragem e análise satisfatórios para a quantificação desses compostos em níveis de concentração tão baixos como em ambientes não poluídos.

De fontes biogênicas os CRE são emitidos para a atmosfera através da redução de sulfato, predominante forma de enxofre em águas e solos óxicos. Dois caminhos importantes participam do ciclo biogeoquímico do enxofre conduzindo à redução assimilatória e dissimilatória do sulfato. ${ }^{10,11}$ No primeiro processo, o íon $\mathrm{SO}_{4}{ }^{2-}$ é assimilado por plantas, bactérias, algas e fungos, sendo reduzido no interior das células e fixado em aminoácidos que possuem o enxofre na sua estrutura molecular, como a cisteína $\left(\mathrm{HSCH}_{2}\right.$ $\left.\mathrm{CHNH}_{2} \mathrm{CO}_{2} \mathrm{H}\right)$ e a metionina $\left(\mathrm{CH}_{3} \mathrm{SCH}_{2} \mathrm{CH}_{2} \mathrm{CHNH}_{2} \mathrm{CO}_{2} \mathrm{H}\right)$. Desta forma, $\mathrm{O} \mathrm{SO}_{4}^{2-}$ é utilizado para a síntese de compostos organossulfurados. Tal processo ocorre tanto em ambientes óxicos quanto anóxicos. A maior parte do enxofre reduzido é fixada no processo de assimilação intracelular e apenas uma pequena fração é liberada como compostos voláteis de enxofre, enquanto os organismos estão vivos. Contudo, após a morte destes seres, os CRE são emitidos para a atmosfera por degradação microbiana, principalmente sob a forma de $\mathrm{H}_{2} \mathrm{~S}^{7}$ No segundo processo, a redução dissimilatória, bactérias redutoras de sulfato como as dos gêneros Desulfovibrio $e$ Desulfotomaculum utilizam no lugar do oxigênio molecular o íon sulfato como receptor de elétrons para a oxidação da matéria orgânica, com a finalidade de obter energia para o desenvolvimento das bactérias em ambientes anóxicos e sustentar o metabolismo respiratório, resultando na formação de sulfeto. ${ }^{11,12}$ Este processo ocorre em solos e sedimentos anóxicos de ecossistemas aquáticos (manguezais, estuários, lagos, rios e oceanos), sendo considerado como o principal caminho para a produção global de $\mathrm{H}_{2} \mathrm{~S}^{7}$

Fontes antrópicas de emissões de CRE para a atmosfera podem ser de origem industrial (refino de petróleo, produção de papel, celulose, fibras de viscose, fungicidas agrícolas, componentes químicos da borracha e solventes), podem ser provenientes da queima de combustíveis fósseis (gasolina, carvão e óleo combustível), de atividades extrativistas (exploração de petróleo e gás natural) e da decomposição da matéria orgânica, tanto urbana quanto rural (esgotos, lixo, aterros sanitários, centrais de tratamento de resíduos). ${ }^{8}$ Outras atividades, como aquelas relacionadas com a agricultura (principalmente pela utilização de fertilizantes) e a corpos d’água eutrofizados, também contribuem para a emissão de compostos reduzidos de enxofre para a atmosfera. ${ }^{13}$

A maioria das reações envolvidas na oxidação dos CRE acontece na troposfera (até cerca de $12 \mathrm{~km}$ de altura), visto que as principais fontes desses compostos se encontram na superfície da terra e nos oceanos. A velocidade de remoção dos CRE da atmosfera é muito rápida, com exceção do COS que possuindo tempo de residência mais longo na troposfera (cerca de um ano) pode ser parcialmente transportado para a estratosfera, onde é mais rapidamente destruído via fotólise. Esses caminhos fotoquímicos são considerados importantes fontes de $\mathrm{SO}_{2}$ e de sulfato na estratosfera. ${ }^{14,15}$

Na troposfera, os CRE são oxidados principalmente por radicais $\mathrm{OH}^{\bullet}$ e $\mathrm{NO}_{3}{ }^{*}$, sendo os principais produtos destas reações o $\mathrm{SO}_{2}$ e MSA $\left(\mathrm{CH}_{3} \mathrm{SO}_{3} \mathrm{H}\right.$ - ácido metano-sulfônico). ${ }^{14,16}$ Estes podem ser posteriormente oxidados a ácido sulfúrico e sais de sulfato, sendo removidos da atmosfera por deposição seca ou úmida. MSA e sulfato, quando incorporados ao aerossol atmosférico, podem contribuir para a acidificação da precipitação, a qual tem um importante papel na acidificação de lagos e solos, danos a florestas, à saúde humana e à vegetação, corrosão de estruturas e monumentos históricos. ${ }^{4}$ Podem atuar também como núcleos de condensação de nuvens, provocando alterações no balanço da radiação da Terra. ${ }^{5,17}$

\section{MÉTODOS DE AMOSTRAGEM PARA COMPOSTOS REDUZIDOS DE ENXOFRE NA ATMOSFERA}

De maneira geral, os métodos de amostragem para componentes do ar atmosférico podem ser divididos em três principais tipos: amostragem passiva, amostragem ativa (contínua e descontínua) e sensoriamento remoto. A Figura 1 esquematiza os principais métodos de amostragem aplicados a CRE na atmosfera.

\section{Amostragem ativa}

$\mathrm{Na}$ amostragem ativa, o ar é succionado para dentro do dispositivo de amostragem com o auxílio de uma bomba a vácuo, sendo necessária a utilização de medidores de fluxo de ar para a determinação do volume de ar ou da taxa de amostragem. Embora o uso de bombas represente uma dificuldade logística, principalmente em áreas remotas, exigindo baterias ou uma linha de energia elétrica, os métodos de amostragem ativa têm sido mais comumente aplicados que aqueles de amostragem passiva no monitoramento de constituintes traços atmosféricos, inclusive dos CRE.

\section{Amostragem contínua}

A técnica de amostragem contínua baseia-se na combinação adequada e automatizada dos sistemas de amostragem e análise, na forma de um instrumento designado por monitor, analisador ou 


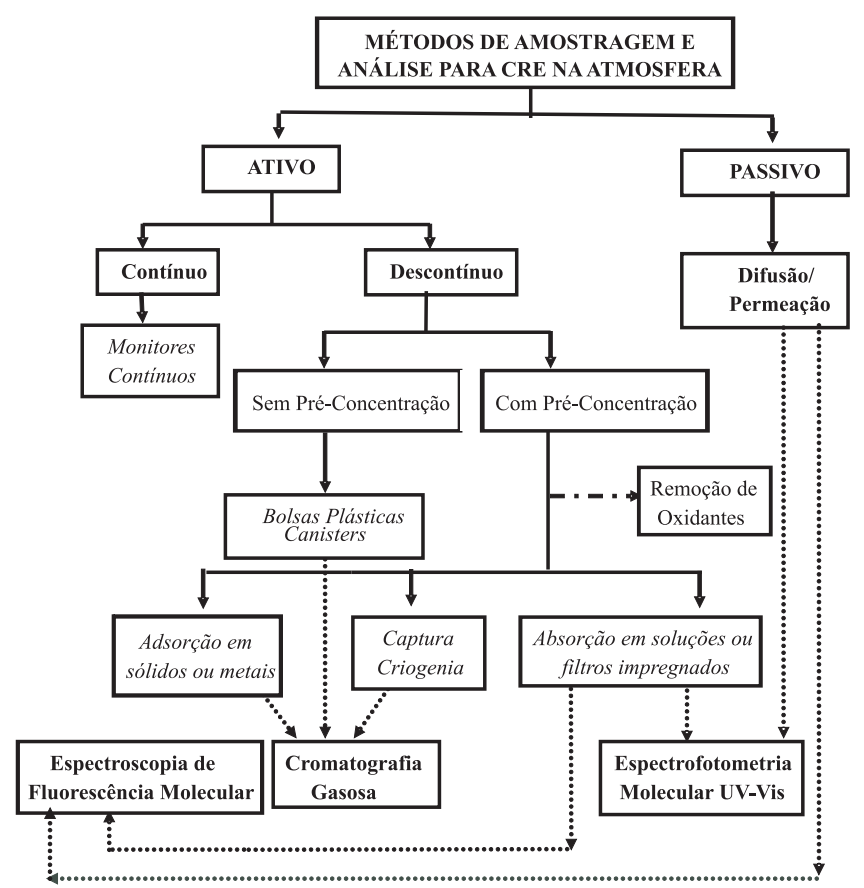

Figura 1. Representação diagramática dos métodos de amostragem e análise para CRE na atmosfera

amostrador contínuo, colocado no local de amostragem por um período adequado para as medidas desejadas. A etapa de análise ocorre em janela de tempo muito pequena, regulada pelo sistema de automatização, ${ }^{18}$ normalmente a partir de $1 \mathrm{~s}$. O funcionamento de amostradores/analisadores contínuos para CRE disponíveis comercialmente ou desenvolvidos em centros de pesquisa, será discutido ao serem tratados os métodos analíticos.

Uma fundamental vantagem da amostragem contínua é a possibilidade de medida das variações das concentrações do poluente em um curto período de tempo, possibilitando a investigação de suas causas. ${ }^{2}$ É bastante útil na identificação de picos de concentração, situações de alerta e acidentes, na avaliação da conformidade da qualidade do ar com padrões de curto prazo, no fornecimento de dados para modelagem e calibração e na avaliação da distribuição temporal de níveis atmosféricos de um dado poluente.

\section{Amostragem descontínua}

A amostragem descontínua é mais utilizada que a contínua, principalmente porque nem todos os métodos de amostragem são passíveis de automatização, e nem sempre podem ser acoplados a um sistema de análise. As amostras são coletadas por um tempo estabelecido, sendo depois transportadas para posterior análise em laboratório. Os resultados obtidos representam uma integração das concentrações na atmosfera local, em um determinado intervalo de tempo. Alguns desses métodos são muito trabalhosos e em comparação com os métodos de amostragem contínuos têm a desvantagem da necessidade de posterior análise em laboratório. No entanto, são normalmente de custo mais baixo e de execução mais fácil.

A amostragem descontínua aplica métodos descontínuos sem pré-concentração (amostragens instantâneas), que envolvem a coleta de amostras em um intervalo de tempo pequeno utilizando recipientes evacuados, como ampolas de vidro, botijões de aço inoxidável ou alumínio, os chamados canisters, ou bolsas plásticas, e métodos de amostragem que pré-concentram a espécie de interesse (amostragens integradas em um tempo determinado), fazendo passar o ar por um meio sorvente ou por um sistema criogênico.

\section{Amostragem sem pré-concentração}

Os dispositivos mais utilizados neste tipo de amostragem aplicada a CRE são as bolsas plásticas e os canisters. Segundo Rudolph et al., ${ }^{19}$ uma importante característica da amostragem utilizando esses recipientes é a eficiência de coleta, que é normalmente de $100 \%$. Entretanto, este método tem duas principais limitações: o volume da amostra é limitado a poucos litros, o que pode ser insuficiente para análise de compostos encontrados em baixas concentrações no ar e a integridade da amostra durante a estocagem é normalmente duvidosa devido à possibilidade de perda dos compostos amostrados por adsorção nas paredes do recipiente, reações químicas entre compostos existentes no ar amostrado ou instabilidade do composto de interesse. Em geral, o método não é adequado para amostragem de compostos de baixa volatilidade ou alta polaridade. ${ }^{2,20}$

Bolsas plásticas flexíveis fabricadas com vários materiais, incluindo Teflon (PTFE), Tedlar, Tedlar aluminizado ou Mylar são relativamente baratas, leves, duráveis, fácies de usar e transportar, e podem ser adquiridas em diferentes tamanhos (5 a 100 L). No entanto, devem ser usadas com precaução devido à grande possibilidade de contaminação da amostra durante a coleta e a estocagem. ${ }^{1,19}$ Algumas bolsas são permeáveis, como tem sido observado, ${ }^{21}$ ocorrendo perdas significativas de amostra quando estocada por longos períodos, ou contaminação da amostra com compostos gasosos que fluem para dentro da bolsa. Estes recipientes contêm alguns resíduos oriundos do seu processamento, por exemplo, enxofre, N,N-dimetilacetamida e outros contaminantes, dependendo da marca e lote da bolsa. Além disso, a limpeza dessas bolsas é feita através do enchimento com ar limpo seguido de evacuação por repetidas vezes, o que favorece efeitos de memória. ${ }^{20}$

Há muito tempo, bolsas feitas de Tedlar vêm sendo preferidas para amostragem de CRE devido à facilidade de manipulação, inércia, resistência e baixo preço. ${ }^{22,23} \mathrm{Lau}^{23}$ examinou a estabilidade de uma mistura gasosa contendo seis compostos de enxofre (em concentrações na faixa de $\mu \mathrm{g} \mathrm{m}^{-3}$ ), em bolsa de amostragem de Tedlar de $5 \mathrm{~L}$, e obteve os seguintes valores de meia-vida para os gases de enxofre: $\mathrm{SO}_{2}$, cerca de $30 \mathrm{~min} ; \mathrm{H}_{2} \mathrm{~S}, 10$ dias; etilmercaptana (EtSH), 25 dias; metilmercaptana (MeSH), 29 dias; $\mathrm{CS}_{2}, 58$ dias e COS, 100 dias. Assim, embora a bolsa de Tedlar não seja satisfatória para a coleta de $\mathrm{SO}_{2}$, o autor considerou-a adequada para amostrar outros compostos dada a estabilidade dos mesmos, encontrada por ele. No entanto, Sulyok et al. ${ }^{24}$ investigaram a estabilidade de estocagem de uma mistura gasosa padrão contendo mercaptanas e sulfetos em bolsas de amostragem de Tedlar padrão e bolsas de amostragem de Tedlar com camada enegrecida; os compostos estudados foram: metilmercaptana $\left(\mathrm{CH}_{3} \mathrm{SH}\right)$, etilmercaptana $(\mathrm{EtSH})$, dimetil sulfeto (DMS), etilmetil sulfeto (MeEtSH), 2-propilmercaptana (2-PrSH), 1-propilmercaptana (1-PrSH), dietil sulfeto (DES), 1-butilmercaptana (1-BuSH) e 2-butilmercaptana (2-BuSH), em concentração de $1 \mathrm{mg}$ $\mathrm{m}^{-3}$ cada em nitrogênio. Os autores verificaram que a estabilidade destes compostos voláteis de enxofre nas bolsas de amostragem de Tedlar padrão é suficiente para análises de rotina, ou seja, dentro do período de 24 a $48 \mathrm{~h}$. Em bolsas de amostragem de Tedlar com camada enegrecida ocorreram perdas significativas (até $10 \%$ para metilmer-captana como o componente mais crítico) depois de 2 dias, provavelmente devido à adsorção dos compostos de enxofre pela camada de carbono negro.

Recipientes de amostragem de vidro geralmente não são utilizados para compostos voláteis de enxofre. Devai e DeLaune ${ }^{25}$ determinaram a influência da matriz gasosa e da umidade sobre a recuperação de uma mistura contendo cinco compostos voláteis de enxofre $\left(\mathrm{H}_{2} \mathrm{~S}, \mathrm{COS}, \mathrm{SO}_{2}, \mathrm{CS}_{2}\right.$ e MeSH, na faixa de concentração de $\mathrm{mg} \mathrm{m}^{-3}$ ) coletados em recipientes de vidro. Em nitrogênio seco, as 
perdas dos analitos eram menores que $5 \%$ depois de $24 \mathrm{~h}$, tendo sido observadas perdas significativas de 10 a $35 \%$ para $\mathrm{CS}_{2}, \mathrm{MeSH}$ e DMS, depois de $48 \mathrm{~h}$. Em ar seco, a mistura permaneceu estável por $3 \mathrm{~h}$, ocorrendo perdas de $10-20 \%$ depois de $24 \mathrm{~h}$ para todos os componentes, exceto $\mathrm{H}_{2} \mathrm{~S}$ que permaneceu estável durante este período. Em ar úmido, as perdas foram de $5 \%$ para $\mathrm{COS}, \mathrm{CS}_{2}$ e DMS, $35 \%$ para $\mathrm{MeSH}$ e $55 \%$ para $\mathrm{H}_{2} \mathrm{~S}$, depois do período de $1 \mathrm{~h}$.

Botijões de aço inoxidável ou alumínio, os conhecidos canisters, causam menos problemas de contaminação que as bolsas e além de permitirem análises múltiplas, dispensarem energia elétrica e não apresentarem problemas de breakthrough (saturação), são robustos e podem ser reutilizados por muitos anos. No entanto, os custos iniciais são elevados e perdas significativas de muitos compostos contendo $\mathrm{O}, \mathrm{N}$ e $\mathrm{S}$ têm sido observadas. Além disso, um severo procedimento de limpeza e a minimização da área interna superficial ativa são essenciais antes do uso, para evitar as perdas por adsorção na superfície. ${ }^{1,26}$

O tratamento da superfície interna dos canisters para redução dos sítios ativos de adsorção é conhecido como passivação e é feito geralmente através do processo $S U M M A,{ }^{27}$ que consiste no eletropolimento do interior dos canisters, enriquecendo a superfície com uma camada de óxido de $\mathrm{Ni}-\mathrm{Cr}$, tornando-a mais inerte que a superfície não tratada. Alguns trabalhos relatam a utilização dos canisters de aço inoxidável eletropolido para a coleta de DMS ou COS, seguida da análise em um intervalo de tempo menor que 1 h. ${ }^{28-30} \mathrm{O}$ canister SUMMA não é adequado para a amostragem de $\mathrm{H}_{2} \mathrm{~S}$ e mercaptanas. ${ }^{31}$ Assim, foi introduzido no comércio o processo alternativo SilcoCan, com revestimento na superfície interna do canister, que elimina sua reatividade a compostos orgânicos voláteis de enxofre. ${ }^{32}$ Adicionalmente, o tratamento Silcosteel (camada inerte de sílica fundida quimicamente ligada à superfície interna do canisters), aumenta a estabilidade de estocagem não apenas para compostos orgânicos, mas também para compostos que reagem com superfícies metálicas, como os que contêm enxofre. ${ }^{24}$ Uma outra técnica de passivação mais recente, é conhecida como Sulfinert ${ }^{33}$ técnica desenvolvida especificamente para utilização em amostragens e transferência de compostos de enxofre em concentrações muito baixas.

A estabilidade das amostras em canisters é o aspecto mais crítico na utilização destes recipientes e vai muito além das características da sua superfície interna, sendo afetada por muitos outros fatores, como pressão de vapor, polaridade, solubilidade, reatividade do composto em água e com outras espécies presentes no ar amostrado, umidade do ar, pressão e temperatura do canister durante a amostragem e armazenamento. ${ }^{34}$

Os estudos realizados para verificar a estabilidade dos CRE nos canisters são poucos. Nguyen et al. ${ }^{35}$ mostraram através de testes realizados em laboratório, que DMS era estável nos canisters de aço inoxidável eletropolido por um período de pelo menos $24 \mathrm{~h}$. Parmar $^{36}$ testou a estabilidade de 4 compostos de enxofre voláteis $\left(\mathrm{H}_{2} \mathrm{~S}, \mathrm{COS}, \mathrm{CS}_{2}\right.$ e $\left.\mathrm{CH}_{3} \mathrm{SH}\right)$ em canister de aço inoxidável com tratamento SUMMA, utilizando concentrações maiores que $1400 \mu \mathrm{g}$ $\mathrm{m}^{-3}$ destes compostos em $\mathrm{N}_{2}$ seco por 3 dias, e concluiu que $\mathrm{H}_{2} \mathrm{~S}$, $\mathrm{COS}$ e $\mathrm{CH}_{3} \mathrm{SH}$ eram instáveis, embora $\mathrm{CS}_{2}$ fosse estável nesse tipo de recipiente durante o período estudado. A perda de COS no canister foi de 8,3\% em 1 dia, 12,3\% em 2 dias e 17,5\% em 3 dias, enquanto que as perdas de $\mathrm{CS}_{2}$ foram relatadas como apenas de 1,$1 ; 1,5$ e $4,2 \%$, respectivamente.

Sulyok et al..$^{24}$ investigaram também a estabilidade de estocagem de mercaptanas e outros sulfetos em canisters com tratamento Silcosteel. Este tipo de canisters foi considerado adequado para amostragem daqueles compostos $\left(\mathrm{CH}_{3} \mathrm{SH}\right.$, EtSH, DMS, MeEtSH, 2-PrSH, 1-PrSH, DES, 1-BuSH e 2-BuSH, todos em concentração de $1 \mathrm{mg} \mathrm{m}^{-3}$ ) com relação à estabilidade dos mesmos. No entanto, as recuperações excederam $100 \%$, especialmente para os compostos com pontos de ebulição mais altos, o que foi atribuído a efeitos de enriquecimento parcial do sistema de amostragem.

\section{Amostragem com pré-concentração}

A pré-concentração em uma amostragem é o processo no qual é aumentada a relação entre microcomponentes, onde estão incluídos traços das espécies químicas de interesse, e macrocomponentes da matriz, influenciando no limite de detecção analítico, reduzindo o efeito de matriz e podendo melhorar a exatidão dos resultados. ${ }^{37}$

Em função das baixas concentrações dos CRE no ar, sua coleta exige normalmente a etapa de pré-concentração. Para isso, as principais técnicas que podem ser utilizadas são: absorção em solução, adsorção em sólidos ou metais, e captura criogênica.

\section{Absorção em soluções ou filtros impregnados}

Nesta técnica, gases ou vapores são absorvidos física ou quimicamente em um líquido ou em uma solução recobrindo um suporte sólido poroso, fixando-se aí ou gerando um novo composto estável. A eficiência do processo de absorção depende principalmente dos seguintes fatores: volume de ar amostrado, volume do líquido absorvente e volatilidade do analito coletado. Assim, podese aumentar a eficiência deste tipo de coleta pela diminuição da temperatura da solução absorvedora, o que reduz perdas do analito por volatilidade, ou pelo aumento do volume de solução absorvedora usando-se dispositivos de coleta em série. Quando a coleta é feita em borbulhadores, a eficiência é inversamente proporcional ao tamanho das bolhas de ar produzidas, além de depender da interação do analito com as moléculas da solução absorvedora, do tempo de reação e do volume de solução. ${ }^{38}$

O uso da técnica de absorção em soluções é antigo e, já em 1957, Jacobs et al. ${ }^{39}$ coletavam $\mathrm{H}_{2} \mathrm{~S}$ borbulhando o ar em uma suspensão de hidróxido de cádmio e determinavam sua concentração utilizando o método do azul de metileno. $\mathrm{O} \mathrm{H}_{2} \mathrm{~S}$ era determinado na faixa de $\mu \mathrm{g} \mathrm{m}^{-3}$, com grandes quantidades de ar amostradas, utilizando longos períodos de tempo ou altos fluxos de amostragem, resultando em baixa eficiência de absorção do $\mathrm{H}_{2} \mathrm{~S}$ atmosférico. Um método mais sensível para a determinação de $\mathrm{H}_{2} \mathrm{~S}$ foi desenvolvido por Axelrod et al.,$^{40}$ borbulhando o ar em solução de $\mathrm{NaOH}$ e analisando posteriormente o sulfeto por uma técnica fluorimétrica. Embora o método possua sensibilidade adequada para concentrações muito baixas, o sulfeto amostrado é instável e a análise necessita ser realizada imediatamente após a amostragem.

Uma séria limitação ao uso de técnicas de retenção úmida é a evaporação do solvente durante o período de amostragem, além da possibilidade de interferência de material particulado, quando apenas gases devem ser amostrados. Essa interferência pode ser minimizada com o uso de um filtro adequado na entrada do ar, apesar do risco de formação de artefatos no filtro por conversão gáspartícula.

Os problemas típicos dos métodos de retenção úmida podem ser evitados utilizando-se filtros ou membranas impregnados com reagente específico que gere composto estável com a espécie de interesse. Esta técnica oferece várias vantagens: pode amostrar grandes quantidades de ar a fluxos altos, sem problemas de evaporação do líquido; os dispositivos são leves, baratos, de fácil transporte, resistentes e de fácil adaptação em métodos automáticos ou semiautomáticos. ${ }^{41}$ Natusch et $a l .{ }^{42}$ desenvolveram um método para a coleta de $\mathrm{H}_{2} \mathrm{~S}$ atmosférico utilizando filtros impregnados com $\mathrm{AgNO}_{3}$. $\mathrm{O} \mathrm{Ag} 2 \mathrm{~S}$ formado era dissolvido em uma solução alcalina de $\mathrm{NaCN}$ e analisado por espectrofluorimetria após a adição de solução alcalina de FMA (acetato de mercúrio e fluoresceína), que reagindo com 
sulfeto provoca diminuição da sua intensidade de fluorescência. O método apresenta sensibilidade de $7 \mathrm{ng} \mathrm{m}^{-3} \mathrm{H}_{2} \mathrm{~S}$, porém mercaptanas e altas concentrações de $\mathrm{O}_{3}$ podem atuar como interferentes.

\section{Adsorção em sólidos ou metais}

Adsorção é um fenômeno de superfície, onde as moléculas são ligadas a um sólido por interações intermoleculares. A força de adsorção depende do tamanho e forma dos poros, e da natureza da superfície adsorvente. ${ }^{2}$

Um adsorvente ideal deve ter as seguintes características: inércia química e estabilidade térmica; capacidade de adsorver quantitativamente e dessorver compostos muito voláteis e semi-voláteis, polares e apolares; estabilidade durante a estocagem; habilidade para adsorver espécies químicas em concentrações muito baixas; capacidade de fornecer baixos valores de brancos e, capacidade de adsorção sem influência da umidade do $\operatorname{ar}^{43}$

Qualquer processo de pré-concentração durante a amostragem deve ser quantitativo para que posteriormente seja analiticamente útil. Assim, em relação a um adsorvente torna-se necessária a avaliação da sua capacidade de amostragem sob determinadas condições. O volume de saturação (breakthrough - BTV) é uma medida freqüentemente usada da capacidade de sorção. O BTV pode ser determinado experimental ou teoricamente. Dentre os fatores que têm importante efeito sobre o BTV pode-se destacar: temperatura, umidade do ar e do sorvente, propriedades físico-químicas do sorvente (área superficial, porosidade, características da superfície), concentração do analito, propriedades físicas e químicas dos gases e vapores, e presença de outros componentes na mistura com possibilidade de serem co-adsorvidos. ${ }^{2}$

Após a amostragem, a recuperação dos analitos para a análise é feita por dessorção térmica (volatilização térmica a temperaturas mais altas que a ambiente) ou extração com solventes. A escolha de uma das técnicas está intimamente ligada ao conjunto adsorbato/ adsorvente utilizado, porém a dessorção térmica é geralmente preferida, pois evita uso de solventes, a diluição da amostra e permite que a amostra total coletada seja injetada em uma coluna cromatográfica, resultando em máxima sensibilidade; a desvantagem é que a amostra só pode ser analisada uma única vez. .,19,20 $^{-}$

Desde 1970, a técnica de pré-concentração de compostos voláteis sobre sólidos adsorventes tem sido aplicada com algumas vantagens: simplicidade, baixo custo, seletividade (com o uso de adsorvente adequado, recheios mistos ou tubos em série), possibilidade de aplicação nos modos ativo e passivo, rapidez de análise com dessorção térmica e cromatografia gasosa. ${ }^{2}$

$\mathrm{O}$ uso de polímeros porosos como adsorventes em dispositivos de amostragem tem sido mais difundido na pré-concentração de compostos voláteis de enxofre, ${ }^{3}$ por alguns motivos: os compostos coletados podem ser dessorvidos mais facilmente em comparação, por exemplo, com o carvão, e a eficiência de coleta é menos influenciada pelo vapor d'água. Dentre os polímeros porosos usados para este fim, Tenax é o mais popular, pois é bastante hidrofóbico, ficando o BTV relativamente independente da umidade; Tenax também possui alta estabilidade térmica e é satisfatório para a coleta de compostos com alta volatilidade. ${ }^{3}$ No entanto, pode sofrer decomposição química em atmosferas altamente oxidantes, e a degradação dos analitos reativos pode ser um sério inconveniente para seu uso. ${ }^{1}$

Tangerman $^{44}$ testou tubos contendo Tenax GC para pré-concentração de alguns compostos voláteis de enxofre $\left(\mathrm{H}_{2} \mathrm{~S}, \mathrm{COS}\right.$ e $\mathrm{CS}_{2}$, tióis, sulfetos e dissulfetos) à temperatura ambiente e a $-196^{\circ} \mathrm{C}$. O excesso de água nas amostras gasosas foi retirado usando $\mathrm{CaCl}_{2}$ antes do adsorvente sólido. À temperatura ambiente, a eficiência do Tenax GC não foi adequada para reter os compostos de enxofre de baixo ponto de ebulição, mas associando a coleta à captura criogênica $\left(\mathrm{N}_{2},-196{ }^{\circ} \mathrm{C}\right)$ este adsorvente mostrou-se eficiente. Zemmelink et al..$^{45}$ utilizaram Tenax TA (resfriado a $-15{ }^{\circ} \mathrm{C}$ ) para pré-concentrar DMS, e salientaram como vantagens da utilização deste adsorvente sua alta capacidade de adsorção a baixas temperaturas, e a facilidade de dessorção do DMS aumentando-se a temperatura para propiciar sua análise por cromatografia gasosa.

Os CRE são também fortemente adsorvidos em peneira molecular 5A (alumino-silicatos), ${ }^{3}$ que permite a entrada de moléculas com diâmetros menores que $5 \AA$ nos seus poros, onde ocorre a adsorção. A utilização de peneira molecular $5 \mathrm{~A}$ para a pré-concentração de $\mathrm{H}_{2} \mathrm{~S}$ e $\mathrm{SO}_{2}$ foi primeiro recomendada, em 1978, por Black et al. ${ }^{46}$ e posteriormente utilizada com sucesso por outros pesquisadores na amostragem de diferentes compostos de enxofre. ${ }^{47,48}$ Este adsorvente possui alto BTV, permitindo a captura não criogênica dos CRE da atmosfera, além de apresentar uma boa recuperação dos compostos dessorvidos: $83-87 \%\left(\mathrm{SO}_{2}\right)$ e $75-82 \%\left(\mathrm{H}_{2} \mathrm{~S}\right){ }^{46}$

Steudler e Kijowski ${ }^{49}$ combinaram a peneira molecular $5 \mathrm{~A}$ com Tenax GC com o objetivo de coletar simultaneamente um maior número de compostos voláteis de enxofre $\left(\mathrm{COS}, \mathrm{H}_{2} \mathrm{~S}, \mathrm{CH}_{3} \mathrm{SH}, \mathrm{CS}_{2}\right.$, $\mathrm{CH}_{3} \mathrm{SCH}_{3}$ e $\mathrm{CH}_{3} \mathrm{~S}_{2} \mathrm{CH}_{3}$ ). Após a pré-concentração dos CRE, estes eram termicamente dessorvidos no laboratório e recoletados em um loop de Teflon, resfriado com $\mathrm{N}_{2}$ líquido, para posterior análise por CG. Apesar dessa montagem não apresentar nenhuma conversão de um composto reduzido em outro, ter uma grande capacidade de adsorção para várias espécies (3-20 $\mu \mathrm{g}$ de S) e ser livre de interferentes, apresentou algumas restrições, como pequena eficiência de recuperação dos CRE adsorvidos (47 a $78 \%$ com umidade relativa do ar variando de 30 a 95\%), longo tempo necessário para ativação dos tubos de adsorção (cerca de 8 h), duração longa de dessorção dos compostos (10 min), além da necessidade de uma segunda etapa de pré-concentração usando criogenia antes da análise cromatográfica, visando obter boa resolução.

Devai e Delaune ${ }^{50}$ avaliaram 14 adsorventes para pré-concentração de COS, sendo este posteriormente dessorvido termicamente e analisado por CG. Os resultados demonstraram que os melhores adsorventes para a coleta de COS foram sílica gel (recuperação de 90,3\%) e Carbotrap 301 (recuperação de 99,7\%), em atmosfera seca. Peneira molecular 5A propiciou uma recuperação de $75 \%$ e, Carbosieve S-III recuperação de 71,7\% em atmosferas úmidas (umidade relativa do ar de $96 \%$ ), utilizando-se $\mathrm{CaCl}_{2}$ como dessecante.

Alguns metais como ouro, paládio e platina possuem a habilidade de quimissorver compostos voláteis de enxofre. Alguns autores descrevem a aplicação de tubos de vidro ou quartzo contendo lã de ouro, pérolas de vidro revestidas com ouro, areia misturada com ouro ou lâminas metálicas na pré-concentração de compostos de enxofre. ${ }^{51-53}$ Davison e Allen ${ }^{48}$ verificaram a ação de sólidos adsorventes combinados com lâmina de ouro e/ou mistura de areia e ouro líquido a $500{ }^{\circ} \mathrm{C}$, e observaram que estes apresentaram perdas excessivas de DMS durante a amostragem e estocagem dos tubos que continham tais sólidos adsorventes.

\section{Captura criogênica}

Captura criogênica, também conhecida por crio amostragem, é a técnica preferida por vários autores para coleta de compostos reduzidos de enxofre em fase gasosa. ${ }^{54-60} \mathrm{~A}$ amostra é succionada, condensada e, em seguida, congelada no interior de um tubo vazio ou empacotado com um material adequado, imerso em um fluido refrigerante. Estes tubos são feitos de vidro, Teflon ou aço inoxidável. De fácil manuseio e limpeza, possuem normalmente dimensões reduzidas (comprimento 8-30 cm, diâmetro interno 3-6 mm, diâmetro externo 4-10 mm) e têm formato de "U", reto ou outras configurações.

Quando não usados vazios, os tubos coletores são geralmente recheados com lã de vidro ou esferas de vidro, que aumentam a 
superfície de contato e a eficiência de coleta. ${ }^{1}$ Alguns autores utilizam tubos empacotados com adsorventes sólidos que retêm fortemente os compostos condensados, não sendo necessário usar temperaturas de congelamento muito baixas. Persson e Leck ${ }^{59}$ usaram lã de vidro dentro dos tubos criogênicos com a finalidade de aumentar a recuperação dos compostos capturados. Os testes mostraram que os tubos imersos em argônio líquido podem ser armazenados durante duas semanas sem perda dos CRE. Haunold et al. ${ }^{55}$ utilizaram, para pré-concentrar CRE, tubos de vidro de borossilicato em forma de "U" imersos em argônio líquido. Cerca de $5 \mathrm{~cm}$ de lã de vidro silanizada foi introduzida na parte inferior dos tubos coletores para aumentar a eficiência de coleta. Pio et al. ${ }^{57}$ pré-concentraram gases de enxofre utilizando tubos coletores de Teflon empacotados com Tenax TA, imersos em uma mistura líquida de nitrogênio e etanol $\left(-117^{\circ} \mathrm{C}\right)$, e verificaram que DMS e COS eram estáveis nestes traps por períodos de pelo menos 10 dias.

Embora a captura criogênica apresente várias vantagens, como a possibilidade de purificação da amostra por retenção seletiva, a fixação de todos os compostos (inclusive os muito voláteis e reativos), elevado fator de pré-concentração, disponibilidade imediata da amostra para análise após descongelamento por aquecimento, ${ }^{2}$ alguns fluidos refrigerantes apresentam desvantagens pela toxicidade dos seus componentes ou pelo difícil manuseio, podendo causar queimaduras na pele e lesões por congelamento, tontura e asfixia. Além disso, podem formar misturas explosivas, como é o caso do $\mathrm{N}_{2}$ líquido que pode condensar oxigênio, que em contato com alguns compostos (principalmente matéria orgânica) também pode originar aquele efeito. Outra desvantagem dessa técnica é que a água condensada pode reagir com outros compostos condensáveis presentes na amostra, além da possibilidade de formação de gelo na entrada de ar, causando entupimento do tubo e diminuindo a eficiência de amostragem. Adicionalmente, altas concentrações de oxidantes (ozônio, óxidos de nitrogênio e peróxidos) presentes na fase condensada podem destruir vários compostos, inclusive alguns CRE como DMS, $\mathrm{H}_{2} \mathrm{~S}$ e $\mathrm{CH}_{3} \mathrm{SH}$, que são bastante reativos. A maioria desses problemas pode ser minimizada pelo uso de um conjunto dessecante/anti-oxidante antes dos tubos criogênicos, porém é necessária uma escolha cuidadosa porque alguns dos dessecantes não são eficazes, outros podem reagir com os analitos ou adsorvê-los. Uma outra solução é fracionar a amostra através do uso de vários tubos dispostos em série, imersos em diferentes fluidos refrigerantes com temperaturas sucessivamente mais baixas. ${ }^{1,19}$ Hofmann et al. ${ }^{60}$ testaram, em laboratório e em campo, o secante Nafion em combinação com enchimento de algodão e verificaram que o conjunto era adequado para ser usado na amostragem criogênica dos CRE, pois impede que estes sejam destruídos na amostragem, com exceção do $\mathrm{CH}_{3} \mathrm{SH}$, o qual é muito sensível à umidade. O mesmo conjunto foi utilizado por Persson e Leck ${ }^{59}$ para impedir a ação de oxidantes/água na coleta simultânea de DMS, $\mathrm{CS}_{2}$ e DMDS.

\section{Depuradores de oxidantes atmosféricos}

Compostos reduzidos de enxofre são rapidamente oxidados por reações com espécies oxidantes como radicais hidroxila e peroxilas, $\mathrm{O}_{3}, \mathrm{NO}_{2}, \mathrm{H}_{2} \mathrm{O}_{2},{ }^{14}$ resultando em perdas significativas durante a amostragem e estocagem. Tais oxidantes estão presentes na atmosfera e são amostrados juntos com os compostos de interesse, a menos que algum procedimento seja feito para evitar que isto aconteça. Esse problema ocorre, especialmente, quando se utilizam métodos de amostragem com pré-concentração, pois aumenta a probabilidade de reação entre os oxidantes e os compostos de interesse sobre a superfície de coleta, sendo, portanto, necessária a remoção destes oxidantes. ${ }^{3,48}$ Para este fim, vários tipos de dispositivos depuradores têm sido sugeridos por diferentes autores, sem, no entanto haver consenso sobre o uso deles na amostragem de CRE. Braman et al. ${ }^{51}$ utilizaram pérolas de vidro cobertas com $\mathrm{Na}_{2} \mathrm{CO}_{3}$ para remover oxidantes do ar quando amostravam DMS. Este mesmo reagente revestindo suporte cromatográfico (Anachrom, Chromosorb) foi usado por Andreae e Raemdonck, ${ }^{61}$ e por Bürgermeister e Georgii. ${ }^{62}$ Um pré-filtro de fibra de vidro impregnado com hidróxido de potássio ou de sódio para a remoção de oxidantes foi utilizado por Bates et al. ${ }^{63}$ e Ayers et al. ${ }^{64}$ Saltzman e Cooper $^{65}$ relataram os resultados obtidos de uma comparação entre Anachrom revestido com $\mathrm{Na}_{2} \mathrm{CO}_{3}$ e um filtro impregnado com $\mathrm{KOH}$, o qual revelou rápida perda de eficiência.

Kittler et al. ${ }^{66}$ compararam a capacidade de vários dispositivos depuradores de oxidantes atmosféricos na amostragem de DMS e concluíram que a eficiência do filtro de fibra de vidro impregnado com uma solução KI/glicerol/Vitex era superior àqueles que utilizavam filtros impregnados com $\mathrm{Na}_{2} \mathrm{CO}_{3}, \mathrm{KOH}, \mathrm{KI}, \mathrm{NaOH}$, Chromosorb $\mathrm{W}$ revestido com $\mathrm{Na}_{2} \mathrm{CO}_{3}$ e grânulos de $\mathrm{MnO}_{2}$. No entanto, embora a reação entre ozônio e iodeto seja rápida, outros oxidantes, como $\mathrm{H}_{2} \mathrm{O}_{2}$, podem requerer vários minutos para sua completa destruição, se isso não ocorrer poderá resultar em concentrações de DMS subestimadas.

Davison e Allen ${ }^{48}$ investigaram a eficiência de alguns dispositivos depuradores de oxidantes atmosféricos em linha, utilizando $\mathrm{Na}_{2} \mathrm{CO}_{3}, \mathrm{FeSO}_{4} \cdot 7 \mathrm{H}_{2} \mathrm{O}$, KI ou $\mathrm{KBr}$, puro ou sobre um suporte cromatográfico (Anachrom P) na amostragem de DMS, em atmosferas remotas marinhas e poluídas. Observaram que todos foram ineficazes na remoção de oxidantes em áreas moderadamente poluídas. Contudo, o uso de KI foi eficiente para remoção de ozônio, em áreas remotas marinhas. Na amostragem de DMS em atmosfera poluída, foi sugerido o contato prolongado da amostra (12 h) com uma solução de $\mathrm{KI} / \mathrm{NaOH}$, para remoção de oxidantes que necessitam de um maior tempo para completa destruição.

Outros autores sugerem o uso de solução aquosa neutra de $\mathrm{KI}^{67}$ e um tubo cheio somente com algodão, ${ }^{58}$ ou combinado com o secante Nafion para reduzir as perdas de $\mathrm{CH}_{3} \mathrm{SH}$, DMS e DMDS em atmosferas úmidas..$^{59,60}$

A Tabela 1 apresenta os métodos ativos descontínuos utilizados na amostragem de CRE.

\section{Amostragem passiva}

$\mathrm{O}$ uso e as bases teóricas da técnica de amostragem passiva foram estabelecidos a partir do trabalho realizado por Palmes e Gunnison, ${ }^{68} \mathrm{em} \mathrm{1973.} \mathrm{Os} \mathrm{autores} \mathrm{desenvolveram} \mathrm{um} \mathrm{amostrador}$ difusivo para determinação de $\mathrm{SO}_{2}$ no ar. Amostradores passivos são dispositivos capazes de fixar gases ou vapores da atmosfera, a uma taxa controlada por processos físicos, tais como difusão ou permeação, não envolvendo o movimento ativo do ar através do amostrador. ${ }^{69}$ Estes amostradores foram inicialmente desenvolvidos para aplicação no monitoramento da exposição pessoal em ambientes de trabalho, onde as concentrações dos poluentes são bastante altas. ${ }^{68,70}$ Entretanto, a partir da década de 80, começaram a ser utilizados no monitoramento ambiental externo, onde as concentrações dos poluentes são muito menores e sofrem influências de condições meteorológicas.

A aplicação dos amostradores passivos no monitoramento de gases ou vapores tem se tornado uma alternativa atraente devido às vantagens que apresentam quando comparados com as técnicas ativas: são simples, de baixo custo, pequenos e leves, facilitando o transporte para locais de difícil acesso, não exigem energia elétrica, calibrações periódicas, medidas do volume de ar amostrado e nem pessoal técnico permanentemente no local de amostragem..$^{71-73}$ Es- 
Tabela 1. Métodos ativos descontínuos usados na amostragem de compostos reduzidos de enxofre (CRE) e respectivos métodos analíticos

\begin{tabular}{|c|c|c|c|}
\hline Método de amostragem & Aplicação a CRE & Método analítico associado & Ref. \\
\hline \multicolumn{4}{|l|}{ Sem pré-concentração } \\
\hline \multirow[t]{2}{*}{ Canisters de aço-inoxidável } & DMS & GC /FPD & $28,30,35$ \\
\hline & COS & $\mathrm{GC} / \mathrm{FPD}$ & 29 \\
\hline \multirow[t]{4}{*}{ Bolsas de Tedlar } & $\begin{array}{l}\text { EtSH, PrSH, n-BuSH, } \\
\text { sec-BuSH, terc-BuSH }\end{array}$ & GC /PID & 22 \\
\hline & $\mathrm{H}_{2} \mathrm{~S}, \mathrm{CH}_{3} \mathrm{SH}, \mathrm{EtSH}, \mathrm{CS}_{2}, \mathrm{COS}$ & $\mathrm{GC} / \mathrm{FPD}$ & 23 \\
\hline & $\begin{array}{l}\mathrm{DMS}, \mathrm{DES}, \mathrm{CH}_{3} \mathrm{SH}, \mathrm{EtSH}, \mathrm{MeEtSH}, \\
\text { 1-PrSH, 2-PrSH, 1-BuSH, 2-BuSH }\end{array}$ & GC /AED & 24 \\
\hline & $\mathrm{H}_{2} \mathrm{~S}, \mathrm{CH}_{3} \mathrm{SH}, \mathrm{DMS}, \mathrm{CS}_{2}$, DMDS & GC /PFPD & $100,104,11$ \\
\hline
\end{tabular}

Com pré-concentração

Absorção em soluções

Suspensão de $\mathrm{Cd}(\mathrm{OH})_{2}$

Solução de $\mathrm{NaOH}$

Solução alcalina de citrato-acetato de zinco

Filtros impregnados com $\mathrm{AgNO}_{3}$

Adsorção em sólidos ou metais

Peneira Molecular 5A e Tenax GC

Peneira Molecular 5A

Tenax GC

Tenax TA

Carbosieve B

Lã de ouro

Pérolas de vidro revestidas de ouro

Captura criogênica

Argônio líquido

Nitrogênio líquido

Oxigênio líquido

\begin{tabular}{|c|c|c|}
\hline $\mathrm{H}_{2} \mathrm{~S}$ & $\begin{array}{l}\text { Espectrofotometria } \\
\text { Molecular UV/Vis }\end{array}$ & 39 \\
\hline $\mathrm{H}_{2} \mathrm{~S}$ & Fluorescência & 40 \\
\hline $\mathrm{H}_{2}^{2} \mathrm{~S}$ & Espectrofotometria & 108 \\
\hline & Molecular UV/Vis & \\
\hline $\mathrm{H}_{2} \mathrm{~S}$ & Fluorescência & $42,53,115,116$ \\
\hline $\mathrm{H}_{2} \mathrm{~S}, \mathrm{COS}, \mathrm{CH}_{3} \mathrm{SH}$ & GC/FPD & 49 \\
\hline $\mathrm{CS}_{2}, \mathrm{DMS}, \mathrm{DMDS}$ & & \\
\hline $\mathrm{H}_{2} \mathrm{~S}$ & GC/FPD & 46 \\
\hline DMS & GC/FPD & 47 \\
\hline $\begin{array}{c}\mathrm{H}_{2} \mathrm{~S}, \mathrm{COS}, \mathrm{CS}_{2} \text {, tióis, } \\
\text { sulfetos, dissulfetos }\end{array}$ & GC/FPD & 44 \\
\hline $\mathrm{DMS}, \mathrm{CS}_{2}$ & GC/FPD & 115 \\
\hline DMS & GC/SCD & 45 \\
\hline DMS, DMDS & GC/MS & 94 \\
\hline $\mathrm{CS}_{2}$ & GC/MS & 86 \\
\hline DMS & GC/FPD & $53,64,66$ \\
\hline $\mathrm{H}_{2} \mathrm{~S}$ & $\mathrm{GC} / \mathrm{FPD}$ & 51 \\
\hline $\mathrm{H}_{2} \mathrm{~S}, \mathrm{COS}$ & GC/FPD & $10,55,56,58,60,117$ \\
\hline $\mathrm{CS}_{2}$ & GC/FPD & $10,55,56,58,59,60,117$ \\
\hline $\mathrm{CH}_{3} \stackrel{2}{\mathrm{SH}}$ & GC/FPD & $10,58,60$ \\
\hline DMS & GC/FPD & $10,55,56,58,59,60$ \\
\hline DMDS & GC/FPD & 56,59 \\
\hline $\mathrm{H}_{2} \mathrm{~S}$ & GC/FPD; GC/MS & $82,95,118$ \\
\hline COS & $\mathrm{GC} / \mathrm{FPD}$ & 118 \\
\hline DMS, $\mathrm{CS}_{2}$ & GC/FPD; GC/SCD & $82,90,118$ \\
\hline $\mathrm{CH}_{3} \mathrm{SH}^{2}$ & GC/FPD & 82,118 \\
\hline DMDS & GC/FPD & 82 \\
\hline $\mathrm{OS}, \mathrm{CH}_{3} \mathrm{SH}, \mathrm{CS}_{2}, \mathrm{DMS}, \mathrm{DMDS}$ & GC/FPD & 54 \\
\hline $\mathrm{COS}, \mathrm{CS}_{2}, \mathrm{DMS}, \mathrm{DMDS}$ & GC/FPD & 116 \\
\hline
\end{tabular}

ses amostradores são bastante úteis na determinação da distribuição espacial da concentração atmosférica de gases em grandes áreas, monitoramento em áreas remotas, fornecimento de dados para modelagem e comparações com padrões de qualidade do ar de longo prazo. Algumas desvantagens no uso de amostradores passivos podem ser citadas: não fornecer concentrações instantâneas e sim concentrações médias semanais e/ou mensais, não permitir alteração da taxa de amostragem, não distinguir episódios transitórios de altas e baixas concentrações em um dado período e não ser indicado como método de referência para monitoramento do ar em normas nacionais ou internacionais.

Para os compostos reduzidos de enxofre encontra-se na literatura a aplicação de amostradores passivos apenas para $\mathrm{H}_{2} \mathrm{~S}$, apesar de poucos terem sido desenvolvidos para avaliação de níveis atmosféricos em ambientes externos. Destes, a maioria tem aplicação no monitoramento da exposição individual de $\mathrm{H}_{2} \mathrm{~S}$ em ambiente de trabalho. Hardy et al. ${ }^{74}$ desenvolveram um amostrador passivo para aplicação em higiene industrial baseado na permeação do $\mathrm{H}_{2} \mathrm{~S}$ através de uma membrana de dimetil silicone. $\mathrm{O}$ desempenho do amostrador não depende da temperatura no intervalo de -3 a $39{ }^{\circ} \mathrm{C}$ e nem da umidade relativa do ar entre 0 e $99 \%$. Alguns autores ${ }^{75-77}$ validaram amostradores passivos para determinar a exposição de trabalhadores a $\mathrm{H}_{2} \mathrm{~S}$ durante a jornada de trabalho.

Shooter et al. ${ }^{72}$ desenvolveram um amostrador passivo difusivo do tipo tubo para medir $\mathrm{H}_{2} \mathrm{~S}$ em ambientes externos, usando telas ou filtros impregnados com nitrato de prata. Baixo limite de detecção permitia a utilização deste amostrador para determinação de baixas concentrações de $\mathrm{H}_{2} \mathrm{~S}$. No entanto, a sua adequação a áreas externas só foi testada em clima temperado e continental. Cruz et al..$^{78}$ vêm trabalhando no desenvolvimento de um amostrador passivo, 
baseado no modelo de Ferm, ${ }^{79}$ para monitoramento ambiental de $\mathrm{H}_{2} \mathrm{~S}$ em condições de altas temperaturas e umidade relativa, características de clima tropical.

\section{MÉTODOS ANALÍTICOS}

A análise de compostos de enxofre em baixas concentrações é complicada devido a alguns fatores, como possibilidade de adsorção em materiais dos dispositivos de amostragem, gerando perdas em consequiência da natureza altamente reativa destes compostos, inadequada sensibilidade ou seletividade, necessidade de sistemas de separação bastante eficazes, pois os compostos de enxofre têm diferentes propriedades físico-químicas, complexidade de muitas metodologias, interferências de outras espécies que podem reagir com estes compostos ou extinguir o sinal do detector, além de custos elevados., ${ }^{3,55}$

Vários métodos analíticos para quantificação de CRE na atmosfera têm sido desenvolvidos: métodos cromatográficos, espectrofotométricos e fluorimétricos. A maioria deles, atualmente, emprega etapas de separação e pré-concentração anterior à detecção para obter informações qualitativas e quantitativas.

\section{Cromatografia gasosa}

A cromatografia gasosa é o método mais freqüentemente utilizado para determinação de baixos níveis de CRE em matrizes gasosas, devido à volatilidade destes compostos, à excelente capacidade de separação associada à facilidade de detecção, além de dispensar o emprego da derivatização. .,80 $^{3}$

A análise de CRE por cromatografia gasosa pode ser feita utilizando-se colunas empacotadas ou colunas capilares. As primeiras são geralmente de Teflon ou vidro. O material e o empacotamento da coluna devem ser escolhidos levando-se em consideração não apenas a completa separação dos componentes da mistura, mas também a necessidade de minimizar as perdas devido à adsorção, que resulta em picos largos e distorcidos, indicando baixa eficiência cromatográfica. As colunas de vidro são baratas, relativamente fáceis de serem preparadas e inertes à maioria dos compostos; a maior limitação é a fragilidade, além de necessitarem de desativação ou silanização antes do empacotamento. ${ }^{81}$ Teflon, também inerte, é o material mais comumente usado em colunas empacotadas para análise de CRE. ${ }^{23,35,47,50,55-59,82-85}$ Os empacotamentos mais utilizados na análise desses compostos são: Chromosil 310 ou $330,,^{23,35,57,59,82,86}$ Carbopack B ou BHT, ${ }^{10,50,55,56,58,60}$ Supelpak S, ${ }^{85}$ Éter polifenil / $\mathrm{H}_{3} \mathrm{PO}_{4}$ sobre Chromosorb T, ${ }^{87}$ Porapack QS. ${ }^{47,84,88,89}$

As colunas capilares de sílica fundida feitas de sílica especialmente purificada contendo quantidades mínimas de óxidos metálicos têm suficiente inércia, ocorrendo poucos problemas de adsorção, além da alta resolução, facilitando assim a análise de traços de compostos de enxofre. Fases não polares, como polissiloxanos, são recomendadas para separação desses compostos. ${ }^{90-92}$ Hutte et al. ${ }^{93}$ avaliaram o efeito da espessura do filme de fase estacionária de metil silicone, comprimento da coluna e diâmetro interno na determinação de compostos de enxofre. Colunas com filmes de 4 a $5 \mu \mathrm{m}$ oferecem uma boa separação dos compostos voláteis de enxofre e são melhor adaptadas às análises de baixas concentrações destes em matrizes gasosas, pois estes filmes retêm solutos altamente voláteis por um tempo mais longo, fazendo com que a separação ocorra em um tempo maior. Colunas tubulares abertas revestidas com polímeros porosos, colunas do tipo PLOT (Porous-Layer Open Tubular), mostraram também ser úteis na análise de compostos de enxofre..$^{90,94,95}$

Os detectores seletivos para enxofre são bastante úteis na análise de compostos de enxofre no ambiente. Sua aplicação reduz o tem- po de análise pela eliminação de procedimentos trabalhosos e demorados de preparação da amostra, que podem causar contaminação ou perdas dos analitos. Uma revisão da aplicação dos detectores seletivos para enxofre na CG foi feita por Wardencki e Zygmunt. ${ }^{96}$

$\mathrm{O}$ detector fotométrico de chama (FPD) é seletivo para enxofre e é o mais largamente usado na análise cromatográfica de CRE no ar. ${ }^{10,55,56,58-60,85}$ Esse detector apresenta além de alta seletividade, outras vantagens como sensibilidade, fácil operação e ampla faixa linear. No entanto, possui desvantagens, como o fator de resposta depende da estrutura molecular do composto analisado (não é equimolar), e a possibilidade de ocorrência de problemas de quenching, quando hidrocarbonetos, água e $\mathrm{CO}_{2}$ são eluídos juntos com os compostos de enxofre. Este último problema pode ser bastante reduzido com o emprego de um FPD de dupla chama, o qual também permite uma resposta mais uniforme, independente da composição ou concentração do analito. ${ }^{96}$ No início da década de 90 , foi lançado no mercado o detector fotométrico de chama pulsada (PFPD) com melhor sensibilidade e seletividade para enxofre e fósforo. ${ }^{77,98}$ Enquanto o FPD, lançado há 30 anos, é geralmente usado somente para S e P, o PFPD detecta também N, As, Sn, Se, $\mathrm{Ge}, \mathrm{Te}, \mathrm{Sb}, \mathrm{Br}, \mathrm{Ga}$, In e $\mathrm{Cu}$, entre outros. ${ }^{99} \mathrm{Na}$ literatura encontrase um número razoável de aplicações desse detector na determinação de CRE na atmosfera. ${ }^{100-104}$ Encontra-se também disponível no mercado o detector de quimioluminescência de enxofre (SCD), o qual apresenta bom desempenho em termos de detectabilidade, seletividade e resposta uniforme para enxofre; adicionalmente, produz uma resposta linear e equimolar para compostos de baixa massa molecular ( $\left.\mathrm{SO}_{2}, \mathrm{SF}_{6}, \mathrm{H}_{2} \mathrm{~S}, \mathrm{DMS}, \mathrm{C}_{2} \mathrm{H}_{5} \mathrm{SH}\right)$, não sofre interferência de água nem de $\mathrm{CO}_{2}$, e a interferência de hidrocarbonetos é minimizada pelo ajuste do tempo de residência da amostra na chama. ${ }^{96,105}$ Outro detector que pode ser utilizado na análise de compostos de enxofre por GC é o detector de emissão atômica (AED), que tem apresentado uma boa combinação de especificidade e sensibilidade para análise de compostos de enxofre voláteis. ${ }^{80,91}$ EckertTilotta et al. ${ }^{105}$ compararam as técnicas de GC-SCD e GC-AED na determinação de compostos orgânicos sulfurados alifáticos e aromáticos. Enquanto o SCD é específico para enxofre, o AED é multielementar, capaz de detectar elementos como P, S, Br, Cl, I, C, H, $\mathrm{N}$, e O. A combinação da cromatografia gasosa (GC) com técnicas espectroscópicas independentes, principalmente espectrometria de massa (MS), tem mostrado que técnicas combinadas são extremamente versáteis para fornecer informações qualitativas e quantitativas referentes a uma variedade de amostras. ${ }^{86,94,95}$

\section{Espectrofotometria molecular}

O método mais comum, que utiliza espectrofotometria molecular UV/Vis para análise de sulfeto em matrizes gasosas, é o método do azul de metileno. ${ }^{39,106,107}$ É baseado no acoplamento oxidativo de duas moléculas de N,N-dimetilfenileno-1,4-diamina (DMPD) com sulfeto, na presença de pequenas quantidades de íon férrico, produzindo o corante azul de metileno, cuja absorção máxima ocorre a $670 \mathrm{~nm}$.

Um segundo método espectrofotométrico que merece destaque é baseado na formação de um produto vermelho-violeta (nitroprussiato), obtido da reação do sulfeto com nitrosilpentacianoferrato (II). Neste método é necessário um controle rígido do $\mathrm{pH}$ do meio (10-12,5), visto que a velocidade da reação de formação do complexo colorido e a sensibilidade do método diminuem bastante em valores de $\mathrm{pH}$ menores que 10; em valores de $\mathrm{pH}$ maiores que 12,5 o reagente se decompõe, diminuindo a quantidade do produto obtido. ${ }^{107}$

Shanthi e Balasubramanian ${ }^{108}$ também usaram a espectrofotometria molecular UV/Vis para determinação de $\mathrm{H}_{2} \mathrm{~S}$ após sua fixação em 
solução alcalina de citrato-acetato de zinco. O método baseia-se na reação do sulfeto com bromato para gerar bromo, que, posteriormente, reage com a diclorofluoresceína. A sensibilidade do produto formado é aumentada com o uso de um surfactante catiônico; a absorvância é medida a $535 \mathrm{~nm}$. Este método foi considerado pelos autores como sendo mais sensível $\left(\varepsilon=4,4 \times 10^{4} \mathrm{~L} \mathrm{~mol}^{-1} \mathrm{~cm}^{-1}\right)$ que o método do azul de metileno $\left(\varepsilon=3,3 \times 10^{4} \mathrm{~L} \mathrm{~mol}^{-1} \mathrm{~cm}^{-1}\right)$ e pode ser usado para determinar $\mathrm{H}_{2} \mathrm{~S}$ até $0,07 \mu \mathrm{g}$.

$\mathrm{O}_{2} \mathrm{~S}$ fixado nos amostradores passivos desenvolvidos por Hardy et $a l .{ }^{74} \mathrm{e}$ por Cruz et al. ${ }^{78}$ também era analisado espectrofotometricamente. No primeiro caso, permeando $\mathrm{o}_{2} \mathrm{~S}$ do ar por uma membrana e posterior reação com uma solução de $\mathrm{NaOH} 2,0 \times 10^{-2}$ mol L-1 e $3,0 \times 10^{-3} \mathrm{~mol} \mathrm{~L}^{-1}$ de EDTA. A solução resultante era tratada com ácido N,N-dimetil-p-fenileno diamina em presença de excesso de $\mathrm{Fe}^{3+}$ e $\mathrm{Cl}^{-}$, formando um produto colorido (azul de metileno) determinado espectrofotometricamente a $670 \mathrm{~nm}$. O limite de detecção era de $14 \mu \mathrm{g} \mathrm{m}^{-3} \mathrm{H}_{2} \mathrm{~S}$ para $8 \mathrm{~h}$ de exposição do amostrador passivo. No segundo caso, $\mathrm{O}_{2} \mathrm{~S}$ presente no ar difunde através do amostrador, sendo fixado posteriormente, reagindo sobre um filtro de celulose impregnado com uma solução de acetato de zinco em meio básico.

\section{Espectroscopia de fluorescência molecular}

Os métodos fluorimétricos possuem sensibilidade de uma a três ordens de grandeza maiores que os métodos espectrofotométricos. Métodos fluorimétricos para determinação de sulfeto podem ser encontrados na literatura. Um deles baseia-se na reação do sulfeto com o complexo mercúrico de 2,2'-piridilbenzimidazola, formando um composto fluorescente resultando, assim, em um aumento da intensidade do sinal. ${ }^{109}$ Outro método baseia-se na diminuição da fluorescência de complexos de acetato de mercúrio-fluoresceína, resultante da ação de supressão da fluorescência causada pelo sulfeto. ${ }^{40}$ Este último método é mais utilizado na análise de sulfeto, onde o acetato de mercúrio-fluoresceína (FMA) reage com sulfeto em meio alcalino, e a fluorescência da solução resultante é determinada com um espectrofluorímetro. Segundo Lawrence et al., ${ }^{110}$ a maior desvantagem deste método é a baixa seletividade quando mercaptanas estão presentes, porque estes compostos reagem via mecanismo similar e podem causar interferência significativa. No entanto, de acordo com o estudo realizado por Jaeschke et al., ${ }^{111}$ os problemas de quenching na análise de $\mathrm{H}_{2} \mathrm{~S}$, causados por outros compostos de enxofre, não são significativos nas faixas de concentração em que esses gases são geralmente encontrados na atmosfera.

A técnica de fluorescência pulsada vem sendo usada para medir continuamente CRE sendo que inicialmente, todo o $\mathrm{SO}_{2}$ presente no ar amostrado é retirado através de um depurador seletivo para não interferir na determinação dos CRE, os quais são então oxidados termicamente a $\mathrm{SO}_{2}$ em um conversor. Em seguida, o $\mathrm{SO}_{2}$ assim produzido é excitado com pulsos de radiação ultravioleta e a fluorescência resultante é monitorada na região de $220-400 \mathrm{~nm}$. A intensidade de fluorescência medida é proporcional à concentração dos CRE., ${ }^{4112}$ Monitores contínuos comerciais, fabricados pela Environnement, utilizam esta técnica para medir a concentração total de CRE e de $\mathrm{H}_{2} \mathrm{~S}$ isoladamente, com limite de detecção igual $1,4 \mu \mathrm{g} \mathrm{m}^{-3}$. As firmas Horiba e Thermo Environmental comercializam monitores contínuos mais sensíveis para determinação de $\mathrm{H}_{2} \mathrm{~S}$ com limite de detecção de $0,70 \mu \mathrm{g} \mathrm{m}^{-3}$.

A técnica também foi usada por Jaeschke et al. ${ }^{111}$ ao desenvolverem um monitor contínuo mais sensível que os encontrados comercialmente para determinação de $\mathrm{H}_{2} \mathrm{~S}$. Este consiste de um sistema de fluxo contínuo acoplado a um espectrofluorímetro, onde o ar é succionado para dentro do monitor, e o $\mathrm{H}_{2} \mathrm{~S}$ atmosférico é absorvido em uma solução de $\mathrm{NaOH} 1,0 \times 10^{-1} \mathrm{~mol} \mathrm{~L}^{-1}$. Uma solução de acetato de mercúrio-fluoresceína (FMA) 2,0 x $10^{-7} \mathrm{~mol} \mathrm{~L}^{-1}$ em $\mathrm{NaOH} 1,0 \times 10^{-1} \mathrm{~mol} \mathrm{~L}^{-1}$ é adicionada à solução contendo traços de sulfeto, e a solução resultante é continuamente transportada por uma bomba peristáltica para o espectrofluorímetro, onde a fluorescência é medida $\left(\lambda_{\text {excitação }}=499 \mathrm{~nm}, \lambda_{\text {emissão }}=520 \mathrm{~nm}\right)$. A calibração do monitor pode ser feita em fase gasosa com o uso de tubos de permeação ou de uma mistura padrão de $\mathrm{H}_{2} \mathrm{~S}$, ou em fase líquida utilizando soluções de sulfeto de sódio. O método determina $\mathrm{H}_{2} \mathrm{~S}$ na faixa de $0,14-18 \mu \mathrm{g} \mathrm{m}^{-3}$, e não sofre interferências de outros CRE ( $\left.\mathrm{CH}_{3} \mathrm{SH}, \mathrm{COS}, \mathrm{CS}_{2}, \mathrm{DMS}\right)$ e nem de $\mathrm{SO}_{2}$, inclusive em concentrações muito altas, acima das encontradas na atmosfera. Nunes ${ }^{113}$ adaptou este monitor às condições tropicais, utilizando-o para a medida de $\mathrm{H}_{2} \mathrm{~S}$ na atmosfera de áreas remotas, urbanas e industriais, no Recôncavo Baiano e em Cubatão-SP.

Shooter et ll $^{72}$ também determinaram fluorimetricamente o sulfeto amostrado passivamente sobre tela ou filtros impregnados com $\mathrm{AgNO}_{3}$, com limite de detecção de $0,07 \mu \mathrm{g} \mathrm{m}^{-3}$ para uma semana de exposição.

\section{CONCLUSÃO}

De acordo com a literatura, os CRE mais determinados na atmosfera são $\mathrm{H}_{2} \mathrm{~S}$ e DMS, seguidos por $\mathrm{CS}_{2}, \mathrm{CH}_{3} \mathrm{SH}$, DMDS e COS. A captura criogênica e a adsorção em sólidos são os métodos de amostragem mais utilizados, e a metodologia analítica mais aplicada, em mais de $60 \%$ da bibliografia consultada para este trabalho, é a cromatografia gasosa com detector fotométrico de chama.

Apesar da complexidade que envolve a determinação dos CRE atmosférico, vários são os métodos de amostragem e análise que têm sido propostos e vêm sendo utilizados para identificação e quantificação destes compostos, predominando o uso daqueles que utilizam etapa de pré-concentração, apresentam alta recuperação dos analitos amostrados, alta resolução na separação dos CRE, mínimas perdas por adsorção e detecção específica para enxofre.

\section{REFERÊNCIAS}

1. Camel, V.; Caude, M.; J. Chromatogr., A 1995, 710, 3.

2. Namiesnik, J.; Talanta 1988, 35, 567.

3. Wardencki, W.; J. Chromatogr., A 1998, 793, 1 .

4. Finlayson-Pitts, B. J.; Pitts Jr., J. N.; Chemistry of the Upper and Lower Atmosphere- Theory, Experiments and Applications, Academic Press: San Diego, 2000.

5. Charlson, R. J.; Lovelock, J. E.; Andreae, M. O.; Warren, S. G.; Nature 1987, 326,655 .

6. WHO - World Health Organization; Air Quality Guidelines for Europe, $2^{\text {nd }}$ ed., WHO Regional Publications, European Series, No. 91: Copenhagen, 2000 .

7. Andreae, M. O.; Jaeschke, W. A. Em Sulphur Cycling on the Continents; Howard, R.; Stewart, I.; Ivanow, M., eds.; John Wiley \& Sons: New York, 1992.

8. Cullis, C. F.; Hirschler, M. M.; Atmos. Environ. 1980, 14, 1263.

9. Aneja, V. P.; J. Air Waste Manage. Assoc. 1990, 40, 469.

10. Jaeschke, W.; Dippell, J.; Sitals, R.; Haunold, W.; Int. J. Environ. Anal. Chem. 1994, 54, 315.

11. Berresheim, H.; Wine, P. H.; Davis, D. D. Em Composition, Chemistry, and Climate of the Atmosphere; Singh, H. B., ed.; Van Nostrand Reinhold: USA, 1995.

12. Warneck, P.; Chemistry of the Natural Atmosphere, Academic Press: USA, 1988.

13. Rice, H.; Nochumson, D. H.; Hidy, G. M.; Atmos. Environ. 1981, $15,1$.

14. Tyndall, G. S.; Ravishankara, A. R.; Int. J. Chem. Kinet. 1991, 23, 483.

15. Crutzen, P. J.; Geophys. Res. Lett. 1976, 3, 73.

16. Sze, N. D.; Ko, M. K. W.; Atmos. Environ. 1980, 14, 1223.

17. Ayers, G. P.; Gras, J. L.; Nature 1991, 353, 834.

18. Boubel, R. W.; Fox, D. L.; Turner, D. B.; Stern, A. C.; Fundamentals of Air Pollution, $3^{\text {rd }}$ ed., Academic Press: USA, 1994. 
19. Rudolph, J.; Muller, K. P.; Koppmann, R.; Anal. Chem. Acta 1990, 236 197.

20. Markert, B.; Environmental Sampling for Trace Analysis, VCH: Germany, 1994.

21. Jayanty, R. K. M.; Atmos. Environ. 1989, 23, 777

22. Stein, V. B.; Narang, R. S.; Anal. Chem. 1982, 54, 991.

23. Lau, Y. K.; Environ. Monit. Assess. 1989, 13, 69.

24. Sulyok, M.; Haberhauer-Troyer, C.; Rosenberg, E.; Grasserbauer, M.; J. Chromatogr., A 2001, 917, 367.

25. Devai, I.; DeLaune, R. D.; Anal. Lett. 1994, 27, 2403.

26. Gholson, A. R.; Jayanty, R. K. M.; Storm, J. F.; Anal. Chem. 1990, 62, 1899.

27. http://www.ndep.nv.gov/fallon/summa.pdf, acessada em Janeiro 2007.

28. Nguyen, B. C.; Mihalopoulos, N.; Putaud, P. J.; Gaudry, A.; Gallet, L.; Keene, W. C.; Galloway, J. N.; J. Atmos. Chem. 1992, 15, 39.

29. Mihalopoulos, N.; Nguyen, B. C.; Putaud, J. P.; Belviso, S.; Atmos. Environ. 1992, 26A, 1383.

30. Putaud, J. P.; Davison, B. M.; Watts, S. F.; Mihalopoulos, N.; Nguyen, B. C.; Hewitt, C. N.; Atmos. Environ. 1999, 33, 647.

31. http://www.caslab.com/FAQsv.php, acessada em Janeiro 2007.

32. http://www.skcinc.com/prod/228-761 asp, acessada em Janeiro 2007.

33. http:// www.restekcoatings.com/treat_sulfinert_rpc.asp, acessada em Janeiro 2007.

34. Kelly, T. J.; Holdren, M. W.; Atmos. Environ. 1995, 29, 2595.

35. Nguyen, B. C.; Mihalopoulos, N.; Belviso, S.; J. Atmos. Chem. 1990, 11, 123.

36. Parmar, S.; EPA/AWMA Int Symp. Report No. EPA600/9 91/018, publication number VIP 21, Air and Waste Management Association: Pittsburgh, 1991.

37. IUPAC; Compendium of Chemical Terminology, compiled by McNaught, A. D.; Wilkinson, A., $2^{\text {nd }}$ ed., Blackwell Science: UK, 1997.

38. ASTM D 1605-60 - Standard Recommended Practices for Sampling Atmospheres for Analysis of Gases and Vapours, American National Standards Institute, 1973.

39. Jacobs, M. B.; Braverman, M. M.; Hochheiser, S.; Anal. Chem. 1957, 29 1349

40. Axelrod, H. D.; Cary, J. H.; Bonelli, J. E.; Lodge Jr., J. P.; Anal. Chem 1969, 41,1856

41. Jaeschke, W. Em Chemistry of Unpolluted and Polluted Troposphere; Georgii, H. W.; Jaeschke, W., eds.; D. Reidel Publishing Company: Dordrecht, 1982.

42. Natusch, D. F. S.; Klonis, H. B.; Axelrod, H. D.; Teck, R. J.; Lodge Jr., J. P.; Anal. Chem. 1972, 44, 2067.

43. Sunesson A.-L.; Nilsson C.-A.; Andersson B.; J. Chromatogr., A 1995, 699 203.

44. Tangerman, A.; J. Chromatogr. 1986, 366, 205.

45. Zemmelink, H. J.; Gieskes, W. W. C.; Holland, P. M.; Dacey, J. W. H.; Atmos. Environ. 2002, 36, 911.

46. Black, M. S.; Herbst, R. P.; Hitchcock, D. R.; Anal. Chem. 1978, 50, 848.

47. Deprez, P. P.; Franzmann, P. D.; Burton, H. R.; J. Chromatogr. 1986, 362, 9.

48. Davison, B. M.; Allen, A. G.; Atmos. Environ. 1994, 28, 1721.

49. Steudler, P. A.; Kijowski, W.; Anal. Chem. 1984, 56, 1432

50. Devai, I.; DeLaune, R. D.; Anal. Lett. 1997, 30, 187.

51. Braman, R. S.; Ammons, J. M.; Bricker, J. L.; Anal. Chem. 1978, 50, 992.

52. Kagel, R. A.; Farwell, S. O.; Anal. Chem. 1986, 58, 1197.

53. Andreae, T. W.; Andreae, M. O.; Bingemer, H. G.; J. Geophys. Res. 1993, 98, 23389

54. Farwell, S. O.; Gluck, S. J.; Bamesberger, W. L.; Schutte, T. M.; Adams, D. F.; Anal. Chem. 1979, 51, 609.

55. Haunold, W.; Georgii, H.-W.; Ockelmann, G.; $L C \bullet G C$ Int. 1992, 5, 28.

56. Simo, R.; Grimalt, J. O.; Albaiges, J.; J. Chromatogr., A 1993, 655, 301.

57. Pio, C. A.; Cerqueira, M. A.; Castro, L. M.; Salgueiro, M. L.; Atmos. Environ. 1996, 30, 3115.

58. Nunes, L. S. S.; Tavares, T. M.; Dippel, J.; Jaeschke, W.; J. Atmos. Chem. 2005, 50, 79 .

59. Persson, C.; Leck, C.; Anal. Chem. 1994, 66, 983

60. Hofmann, U.; Hofmann, R.; Kesselmeier, J.; Atmos. Environ. 1992, 26, 2445.

61. Andreae, M. O.; Raemdonck, H.; Science 1983, 211, 744.

62. Bürgermeister, S.; Georgii, H. W.; Atmos. Environ. 1991, 25A, 587.

63. Bates, T. S.; Johnson, J. E.; Quinn, P. K.; Goldan, P. D.; Kuster, W. C.; Covert, D. C.; Hahn, C. J.; J. Atmos. Chem. 1990, 10, 59.

64. Ayers, G. P.; Ivey, J. P.; Gillett, R. W.; Nature 1991, 349, 404.

65. Saltzman, E. S.; Cooper, D. J.; J. Atmos. Chem. 1988, 7, 191.

66. Kittler, P.; Swan, H.; Ivey, J.; Atmos. Environ. 1992, 26A, 2661.

67. Cooper, D. J.; Saltzman, E. S.; J. Atmos. Chem. 1991, 12, 153.

68. Palmes, E. D.; Gunnison, A. F.; Am. Ind. Hyg. Assoc. J. 1973, 34, 78.

69. Brown, R. H.; Harvey, R. P.; Purnell, C. J.; Saunders, K. J.; Am. Ind. Hyg Assoc. J. 1984, 45, 67.
70. Palmes, E. D.; Gunnison, A. F.; DiMattio, J.; Tomczyk, C.; Am. Ind. Hyg. Assoc. J. 1976, 37, 570.

71. Rose, V. E.; Perkins, J. L.; Am. Ind. Hyg. Assoc. J. 1982, 43, 605

72. Shooter, D.; Watts, S. F.; Haynes, A. J.; Environ. Monit. Assn. 1995, 38, 11

73. Cruz, L. P. S.; Campos, V. P.; Quim. Nova 2002, 25, 406.

74. Hardy, J. K.; Strecker, D. T.; Savariar, C. P.; West, P. W.; Am. Ind. Hyg. Assoc. J. 1981, 42, 283.

75. Kring, E. V.; Damrell, D. J.; Henry, T. J.; DeMoor, H. M.; Basilio, Jr. A N.; Simon, C. E.; Am. Ind. Hyg. Assoc. J. 1984, 45, 1

76. McConnaughey, P. W.; McKee, E. S.; Pritts, I. M.; Am. Ind. Hyg. Assoc. J. 1985, 46, 357.

77. McKee, E. S.; McConnaughey, P. W.; Am. Ind. Hyg. Assoc. J. 1986, 47, 475 .

78. Cruz, L. P. S.; Campos, V. P.; Alves, E. M.; Tavares, T. M.; Resumos da $30^{a}$ Reunião Anual da Sociedade Brasileira de Química, Águas de Lindóia, Brasil, 2007.

79. Ferm, M.; A sensitive diffusional sampler. IVL Report L91-172. Swedish Environmental Research Institute, Göteborg: Sweden, 1991.

80. Gerbersmann, C.; Lobinski, R.; Adams, F. C.; Anal. Chim. Acta 1995, 316, 93.

81. Grob, R. L.; Modern Practice of Gas Chromatography, $3^{\text {rd }}$ ed., WileyInterscience Publication, John Wiley \& Sons Inc.: USA, 1995

82. Leck, C.; Bagander, L. E.; Anal. Chem. 1988, 60, 1680.

83. Castello, G.; D‘Amato, G.; Nicchia, M.; J. Chromatogr. 1990, 521, 99.

84. Gaffney, J.S.; Spandau, D. J.; Kelly, T. J.; Tanner, R. L.; J. Chromatogr. 1985, 347, 121.

85. Lindgren, E. R.; Pershing, D. W.; Kirchgessner, D. A.; Drehmel, D. C.; J. Chromatogr. 1991, 585, 353.

86. Bandy, A. R.; Tucker, B. J.; Maroulis P. J.; Anal. Chem. 1985, 57, 1310.

87. Thornton, D. C.; Bandy, A. R.; Ridgeway, R. G.; Driedger III, A. R.; Lalevi, M.; J. Atmos. Chem. 1990, 11, 299.

88. Souza, T. L. C.; Bhatia, S. P.; Anal. Chem. 1976, 48, 2234.

89. Huber, L.; Obbens, H.; J. Chromatogr. 1985, 349, 465.

90. Ivey, J. P.; Swan H. B.; Anal. Chim. Acta 1995, 306, 259.

91. Deruaz, D.; Sousan-Marchal, F.; Joseph, I.; Desage, M.; Bannier, A.; Brazier, J. L.; J. Chromatogr. 1994, 677, 345.

92. Nedjma, M.; Maujean, A.; J. Chromatogr., A 1995, 704, 495.

93. Hutte, R.S.; Johansen, N.G.; Legier, M. F.; J. High Resolut. Chromatogr. 1990, 13, 489

94. Yokouchi, Y.; Bandow, H.; Akimoto, H.; J. Chromatogr. 1993, 642, 401

95. Jacobsson, S.; Falk, O.; J. Chromatogr. 1989, 479, 194

96. Wardencki, W.; Zygmunt, B.; Anal. Chem. Acta 1991, 255, 1.

97. Atar, E.; Cheskis, S.; Amirav, A.; Anal. Chem. 1991, 63, 2061

98. Cheskis, S.; Atar, E.; Amirav, A.; Anal. Chem. 1993, 65, 539.

99. http://www.shsu.edu/ chemistry/PFPD/pfpd.html, acessada em Julho 2006.

100. Kim, K.-H.; Jeon, E. C.; Choi, Y. J.; Koo, Y. S.; Atmos. Environ. 2006, $40,4478$.

101. Kim, K.-H.; Ju, D. W.; Joo, S. W.; Talanta 2005, 67, 955.

102. Kim, K. H.; Swanb, H.; Shonc, Z. H.; Leed, G.; Kime, J.; Kangf, C. H.; Chemosphere 2004, 54, 515.

103. Li, K. C.; Shooter, D.; Int. J. Environ. Anal. Chem. 2004, 84, 749.

104. Shon, Z. H.; Kim, K. H.; Jeon, E. C.; Kim, M. Y.; Kim, Y. K.; Song, S. K.; Atmos. Environ. 2005, 39, 4803.

105. Eckert-Tilotta, S. E.; Hawthorne, S. B.; Miller, D. J.; J. Chromatogr. 1992, 591, 313.

106. Budd, M. S.; Bewick, H. A.; Anal. Chem. 1952, 24, 1536.

107. Kuban, V.; Dasgupta, P. K.; Marx, J. N.; Anal. Chem. 1992, 64, 36.

108. Shanthi, K.; Balasubramanian, N.; Analyst 1996, 121, 647.

109. Bark, L. S.; Rixon, A.; Analyst 1970, 95, 786.

110. Lawrence, N. S.; Davis, J.; Compton, R. G.; Talanta 2000, 52, 771.

111. Jaeschke, W.; Schunn, H.; Haunold, W.; Fresenius J. Anal. Chem. 1995, 351, 27.

112. Torvela, H.; Measurement of Atmospheric Emissions, Springer-Verlag: London, 1994

113. Nunes, L. S. S.; Dissertação de Mestrado, Universidade Federal da Bahia, Brasil, 1995.

114. Kim, K.-H.; Atmos. Environ. 2006, 40, 6567.

115. Cooper, D. J.; Saltzman, E. S.; J. Geophys. Res. 1993, 98, 23397.

116. Lamb, B.; Westberg, H.; Allwine, G.; Bamesberger, L.; Guenther, A.; J. Atmos. Chem. 1987, 5, 469.

117. Dippell, J.; Jaeschke, W.; J. Atmos. Chem. 1996, 25, 251.

118. Goldan, P. D.; Kuster, W. C.; Albritton, D. L.; Fehsenfeld, F. C.; J. Atmos. Chem. 1987, 5, 439 . 